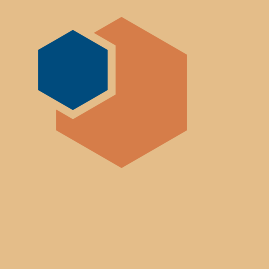

\section{India to reopen mining for rare-earth elements}

$T_{1}$

he battle over rare earths seems to have become the most bitter international trade dispute this decade. Countries have become increasingly concerned that China is gaining a monopoly over the production of these elements, which are critical to green energy and high-tech industries. The United States, for example, once produced all its rareearth elements domestically, but has become wholly reliant on Chinese imports over the last 15 years. During disputes through the World Trade Organization, China said that its policies in question are aimed at protecting natural resources and achieving sustainable economic development. Meanwhile, one of the few solutions for countries suffering a supply shortage is to launch their own mining efforts. And that is exactly what China's neighbor, India, is now planning to do.

India's Ministry of Mines has formed a steering committee to investigate restarting exploration of rare earths, with a particular eye on India's growing renewable energy sector. Modern electronic technologies depend on rare earths, and with government targets for a total ca-

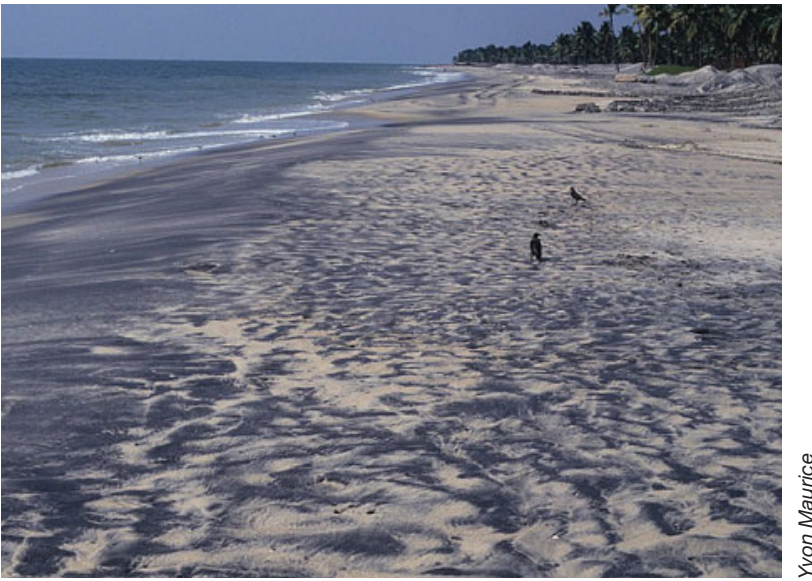

Mineral-rich "black sands" in Kollam, a coastal district in the Indian state of Kerala. These sands are a valuable source of monazite. pacity of $20 \mathrm{GW}$ of on-grid solar power by 2022 , and $40 \mathrm{GW}$ of wind power, the Geological Survey of India has made exploration of rare earths a high priority for its next five-year plan.

"With limited availability of rare earths, and the projected growth in demand, supply chain vulnerability may set in," said Rangachari Krishnan, chief advisor to the Center for Study of Science, Technology and Policy in Bangalore, and former head of the Metallurgy Division at the Bhabha Atomic Research Centre.

The elements particularly in demand include neodymium, which is used in the permanent magnets inside the compact motors of wind turbines, and dysprosium, which is used to raise the Curie temperature of the magnets of electric vehicles. "The typical weight of a 1-MW wind generator is around 600 kilograms, out of which neodymium is around $25 \%$ and dysprosium is about two to three percent," said Krishnan. Cerium oxide is used for UV absorption in solar panels, and lanthanum is required for catalytic cracking in the petroleum industry. India also has a large and increasing demand for fluorescent bulbs and tube lights, which use terbium, yttrium, and europium in their fluorescent coatings.

If India does begin mining rare earths, it will not be for the first time. "India was a leading producer and supplier of rare earths 50 years ago," said Krishnan, particularly of yttrium. About five years ago, however, the country froze mining and development

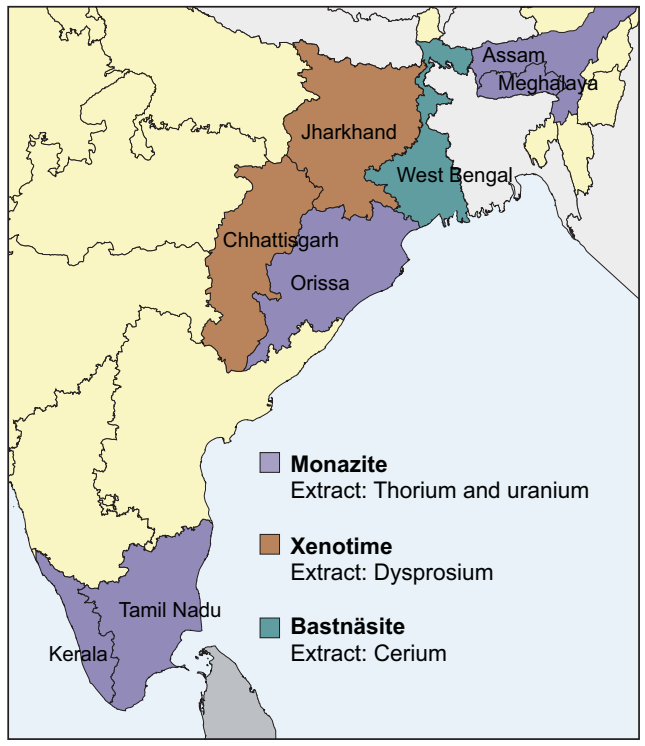

of rare-earth elements because of a lack of competition in the domestic market, which made Chinese imports cheaper.

Now, as before, the Atomic Minerals Directorate, a unit of India's Department of Atomic Energy, is at the heart of exploration since a major source of rare earths is monazite sands, from which radioactive thorium and uranium are also extracted. "India possesses the largest deposits of monazite in the world, mostly in the coastal tracts of Orissa on the east coast and in Kerala on the west coast. Besides the beach sands, monazite has been reported in carbonatites in Meghalaya, Tamil Nadu, and Assam," said Krishnan.

According to the Prime Minister's office, these reserves stand at about 10.7 million tons, translating to roughly 5 million tons of rare-earth oxide.

Indian Rare Earths Ltd. (IREL), the country's only rare-earths producer, is setting up a processing plant in the eastern state of Orissa to produce 11,000 tons of rare-earths chloride, which in turn can be converted to rare-earth oxides. Along with a smaller plant already in operation in Kerala, they are expected to produce around 2250 tons of rare-earth oxides in the last quarter of 2012.

The Japanese firm Toyota Tsusho has entered into an agreement with IREL to set up a plant at Visakhapatnam in Eastern India to produce rare-earth oxides, and the company expects an export of about 4000 tons of the material from this 
plant. In July 2011, it began construction of a plant that "makes use of this previously unexploited mixture as a raw material to produce such rare earths as neodymium, lanthanum, and cerium," according to the company's website.

Sizable deposits of xenotime, a phosphate mineral that contains the heavier rare earth dysprosium, have also been found in the states of Chhattisgarh and Jharkhand. Meanwhile, bastnäsite - a source of cerium - has been found in the state of West Bengal. As yet, though, the extent of India's reserves is not fully known. Of the 6500 kilometers of Indian coastline, the Geological Survey of India has only explored 2200 kilometers, according to Krishnan. He also warns that the process of starting such mining operations is likely to be slow: "From exploration until setting up an extraction plant may take more than 10 years."

Despite its latest efforts, however, India is unlikely to challenge China in its dominance over the global supply of rare earths, according to Naresh Pant, associate geology professor at the University of Delhi. "That would require at least an order of magnitude increase in production," he said. India's rare-earth reserves stand at just more than three million tons, he said, while China has more than 36 million.

At the moment, the lack of rare-earth deposits in the European Union means that it imports USD $\$ 458$ million of rare earths annually from China. According to the US Department of the Interior, the United States has around 13\% of global reserves of rare earths, Russia has $17 \%$, and Australia has $1.5 \%$, yet all these nations depend on imports, too. Complaints to the World Trade Organization have focused on the fact that China - which has around $37 \%$ of reserves and supplies around $97 \%$ of the world's rare-earth elements - is threatening businesses by restricting exports.

For India, which also relies on Chinese rare earths, restarting rare-earths processing, mining, and exploration may at least offer a ray of hope as supply shortages begin to bite.

Angela Saini
NSF and EC establish collaboration opportunities

for early career scientists

$\mathbf{T}$ The US National Science Foundation (NSF) and the European Commission (EC) signed an Implementing Arrangement to provide opportunities for NSF-funded early career scientists and engineers to pursue research collabo- rations with European colleagues supported through the European Research Council (ERC) awards. The agreement supports collaborations on specific projects while leveraging research funding and fostering lasting collaborations be- tween European and US researchers.

European Commissioner for Research, Innovation and Science Máire Geoghegan-Quinn and NSF Director Subra Suresh signed the arrangement on July 13 at the European Science Open Forum in Dublin.

\section{Brazil and China discuss 10-year cooperation plan}

D uring the Rio +20 Summit held in June, Brazil and China signed the Ten-Year Cooperation Plan 2012-2021. In July, Brazil's Minister of Science, Technology and Innovation (MCTI),
Marco Antonio Raupp, traveled to China to meet with the Chinese Ministers of Science and Technology, Wan Gang, and Industry and Information Technology, Miao Wei, and the head of the Chinese
National Space Administration (CNSA), Chen Qiufa, to discuss numerous topics, including the Bi-National Center for Nanotechnology and memorandums of understanding for biotechnology and meteorology centers.
Australia's synchrotron receives renewed funding

www.synchrotron.org.au

M onash University, with the support of the Australian government's investment of AUD $\$ 30$ million under Prime Minister Julia Gillard, will manage the Australian Synchrotron program. Australian universities will also invest around AUD\$25 million. Announcing the funding, Science and Research Min- ister Senator Chris Evans said with the strong need to undertake research and development to transform industries and see them through challenges such as climate change, economic change, and skills shortages, there has never been a more vital time to invest in the facility.

"As the Australian Synchrotron can be used to study the most precise nature of any biological and industrial material, it can be used by almost any industry across a wide range of research fields," said Evans.

The AUD\$30 million government investment is being provided by the Australian Research Council (AUD\$25 million) and National Health and Medical Research Council (AUD\$5 million). 